\title{
A Proposed Prototype on using Online Social Networks as Learning Platforms
}

\author{
Carina Titus \\ University of Dodoma \\ P O Box 490, Dodoma, Tanzania
}

\begin{abstract}
The fields of Learning Management Systems (LMSs) is full of open source and commercial products including Blackboard, WEB CT, and Moodle. These systems are tutor-oriented, not designed to facilitate personalized learning support for an individual learner. Instructors and students, frustrated with current LMS, need a new, innovative, user-friendly alternative to encourage and empower students to take control of their education, and teachers to explore new styles of teaching, depending on their students' needs. This paper introduces a prototype which shows how OSNs can be used as e-learning platform for a simple, dedicated, learner-oriented e-learning system to facilitate the learning process. This prototype is meant to stimulate the use of OSNs for educational purposes for less technically savvy students.
\end{abstract}

\section{Keywords}

Social media, Social networks, Web 2.0, University students, The University of Dodoma.

\section{INTRODUCTION}

Virtual communities constructed through OSNs enable learners to connect and collaborate on global platforms, transcending geographical boundaries [10]. Removing these boundaries increases communication, collaboration, and engagement [10]. In the shared forum provided by OSNs, learners can construct a shared understanding, engage and collaborate in discussions, while sharing common resources, such as readings, links, and videos.

Focusing specifically on online education, [4] studied an online undergraduate course taught via the Elgg social networking platform. While their findings reveal that the learner experience was generally positive, they also discovered that students were "lost in social space" and needed support and scaffolding to participate in the social network. Despite such dangers OSNs seems to be a vital alternatives to LMSs or their complements.

\section{BACKGROUND OF THE STUDY}

Regardless of their reported success, LMSs are relatively inflexible systems for many students. In LMSs, the standard organizational unit is the course, and this structure restricts students to the content designed for a particular course and to interact only with other participants of the course. Therefore, students' engagement in LMS is lower in contrast to their engagement in other environments or tools such as mobile devices, Web 2.0 tools or game consoles. These environments provide opportunities for customization, communication and a sense of ownership impossible in current LMSs [11].

Use of OSNs as platforms where different people meet and share their experience by publishing their ideas, action and even events, can create a new learning environment in the context of different learning settings. These sites can support a range of applications associated with educational technologies already in use at the university level such as communication, participation, interactivity and collaboration. This paper aimed at proposing a prototype which shows how OSNs can be used as e-learning platforms in Tanzania higher learning context.

\section{RELATED WORK}

According to [2], tertiary students, teenagers and young people are the main users of OSNs. Because the predominant users of OSNs are school and college students, this is a sufficient reason for the education industry to attract students to use social networks as learning tools.

OSNs can facilitate learning and skill development outside formal learning environments by supporting peer-to-peer learning of knowledge and skills, collaboration, diverse cultural expression, the development of skills valued in the modern workplace, and a more empowered conception of citizenship [7]. Furthermore, because of the high level of agency and personalization involved, OSNs can be particularly important learning spaces for young people who struggle in traditional educational settings [6]. Beyond substantial educational benefits studies have shown that OSNs support informal learning interests and needs such as online marketing, advanced ICT and creative content production as well as parenting methods for young parents [12]. Such studies show that OSNs constitute new avenues for engaging young people in learning activities. When sharing content and creating/maintaining relationships young people engage in peer -based, self-directed and interactive learning (accessible from outside the classroom), essential for engagement and deep learning [7].

Furthermore, the knowledge and skills young people are learning through OSNs are directly relevant to the participatory web in which user generated content is now integrated in a rapidly developing online business model that capitalizes on the social networks, creativity and knowledge of its users and this means that new business models are expected to emerge [13]. This has led some to claim that the learning enabled via OSNs and social media will have a direct bearing on their economic futures [12].

\section{PROPOSED PROTOTYPE}

The objective of this phase of project is to construct the design elements for a web-based e-learning prototype that can be used to enhance the learning process through OSN at Tanzanian Universities. UML diagrams were used to model data for the proposed prototype. UML is chosen as a modeling language because it is a programming language independent. UML provides several types of diagrams that, when used within a given methodology, increase the ease of understanding an application under development. 
From the answers of the respondents the model was proposed. That may serve as a platform by allowing the connections between students preferences found in the requirement elicitation with the current data available; hence the approach that was used for the development of the prototype is the evolutionary prototyping model. This approach presupposes gradual refinement of the prototype and allows for, or adapts to, changes that take place within an organization until a usable product emerges.

For the proposed system, two structural components (Use case diagram and Class diagram), and one behavioral feature (Sequence diagram) were presented, using Visual Paradigm for UML 8.0, Community Edition [19] for depicting these diagrams.

\subsection{Use case Diagram}

It is important to properly model the user's characteristics in order to understand the roles and variation between users [1]. Use case modeling is the way of showing how the system stakeholders will interact with the system. Developing use case helps to understand system requirements in details. In this case, the use case model shows the interaction between the system users and the system administrator, and how they interact with the central database which acts as the main system for data storage and retrieval. The proposed prototype includes three actors; Administrator(s), Instructors and Students. Each actor interacts and participates in a set of use cases as shown in Figure 3.

\subsection{Class Diagram}

This is static structure diagram that describes the structure of a system by showing the system's classes, their attributes, operations (or methods), and the relationships among the classes. Figure 2 shows the main classes of the system and how they interact with each other.

\subsection{Sequence Diagram}

A sequence diagram shows object interactions arranged in time sequence. It depicts the objects and classes involved in the scenario and the sequence of messages exchanged between the objects needed to carry out the functionality of the scenario. Sequence diagrams are typically associated with use case realizations. In this section sequence diagrams for the system were modeled as detailed in the Figure 4.

\subsection{Design Architecture of the Prototype}

This session contains the architectural of the proposed prototype. Figure 1 shows a social learning 3-tier architectural framework involving a user accessing applications from a web server. On this architecture, at anytime and from any location, students and instructors can access the Social Networks Sites (SNSs) browser using different communication devices such as WAP Phones PC/Laptop, Pocket PC and PDA. E-Learning Database Server and E-Learning Web Server used to store the learning materials, video/audio data and other value-added information and content that e-learning community members wish to access.

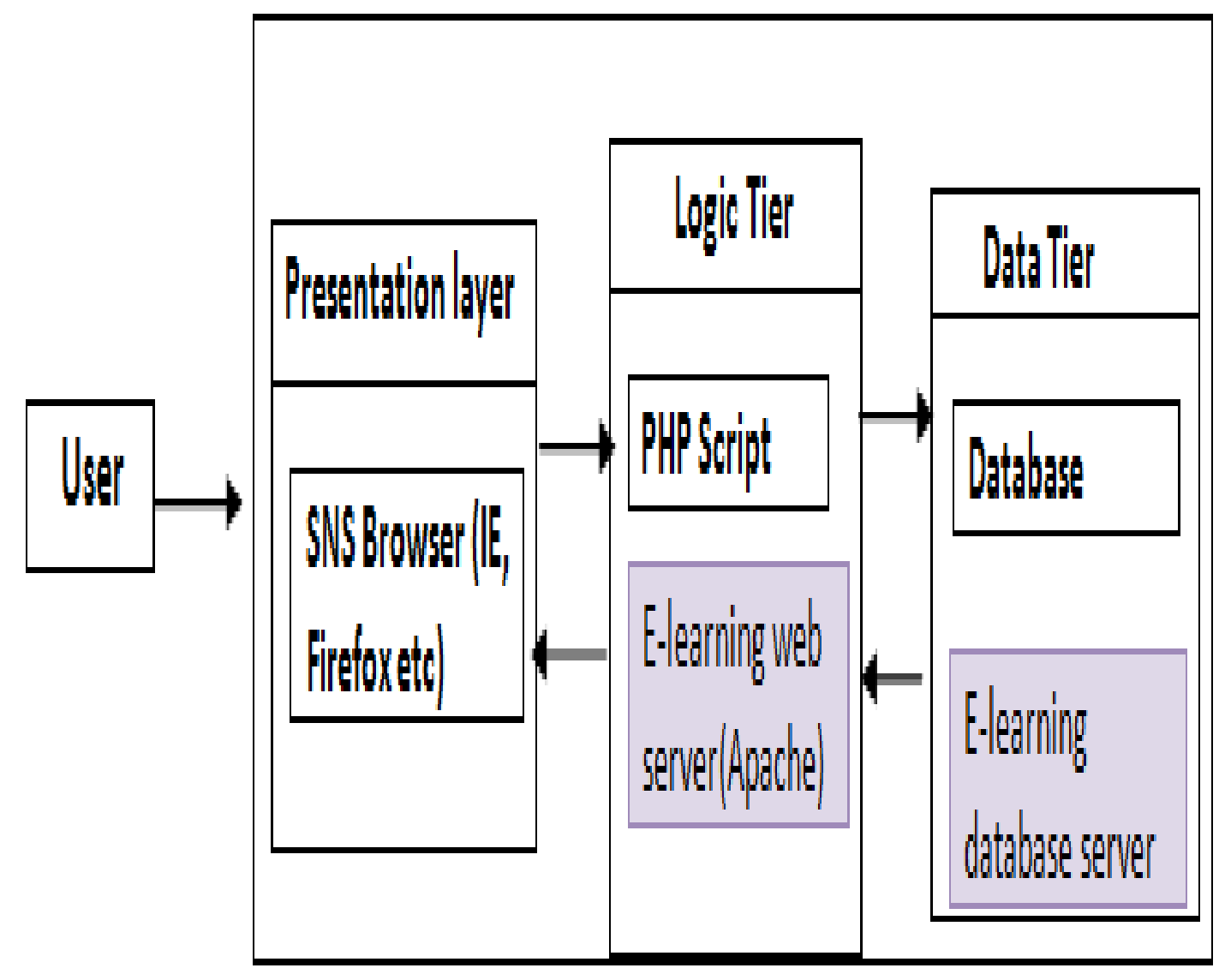

Figure 1: Design Architecture of the Prototype 


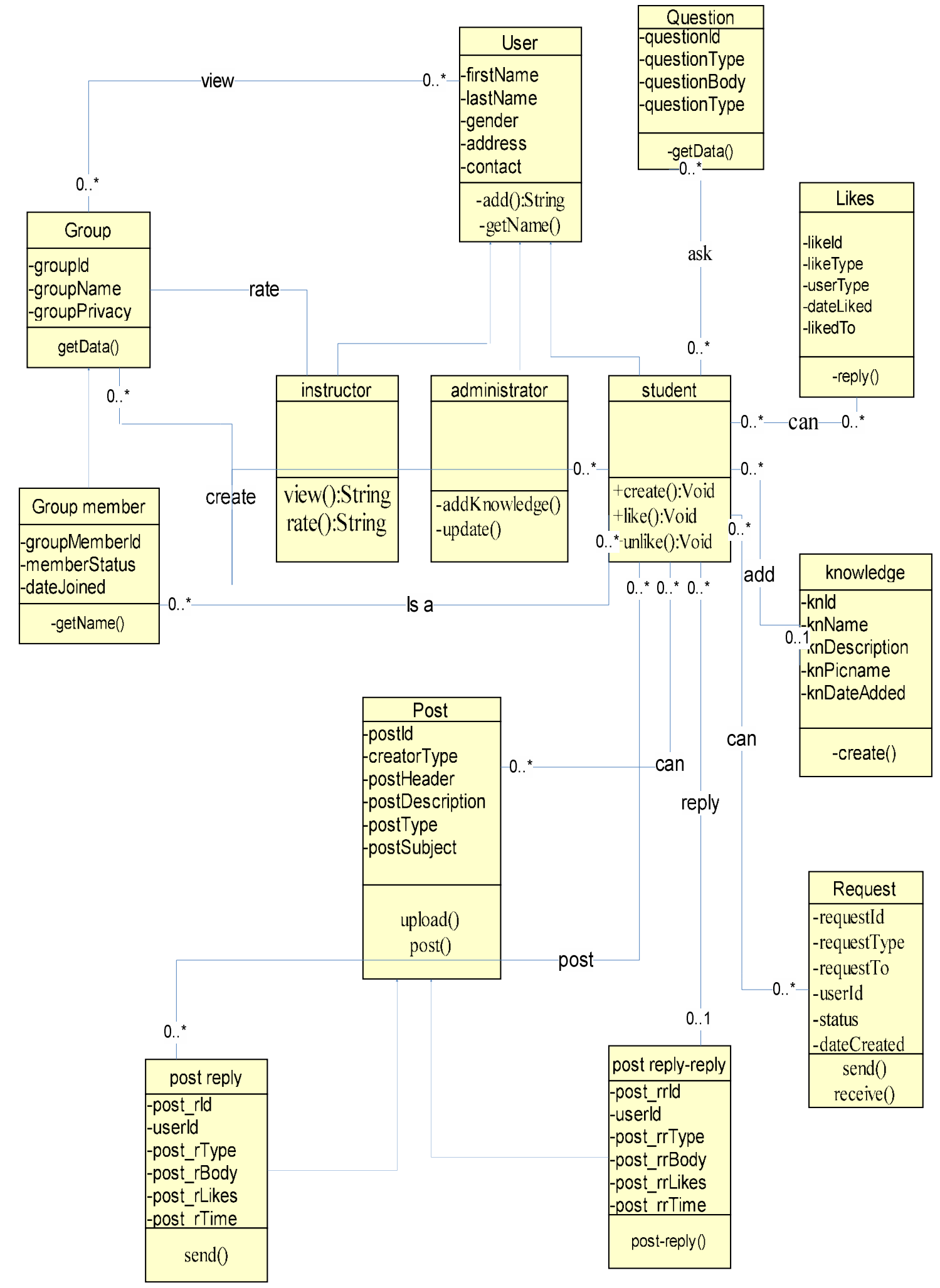

Figure 2: Class Diagram 


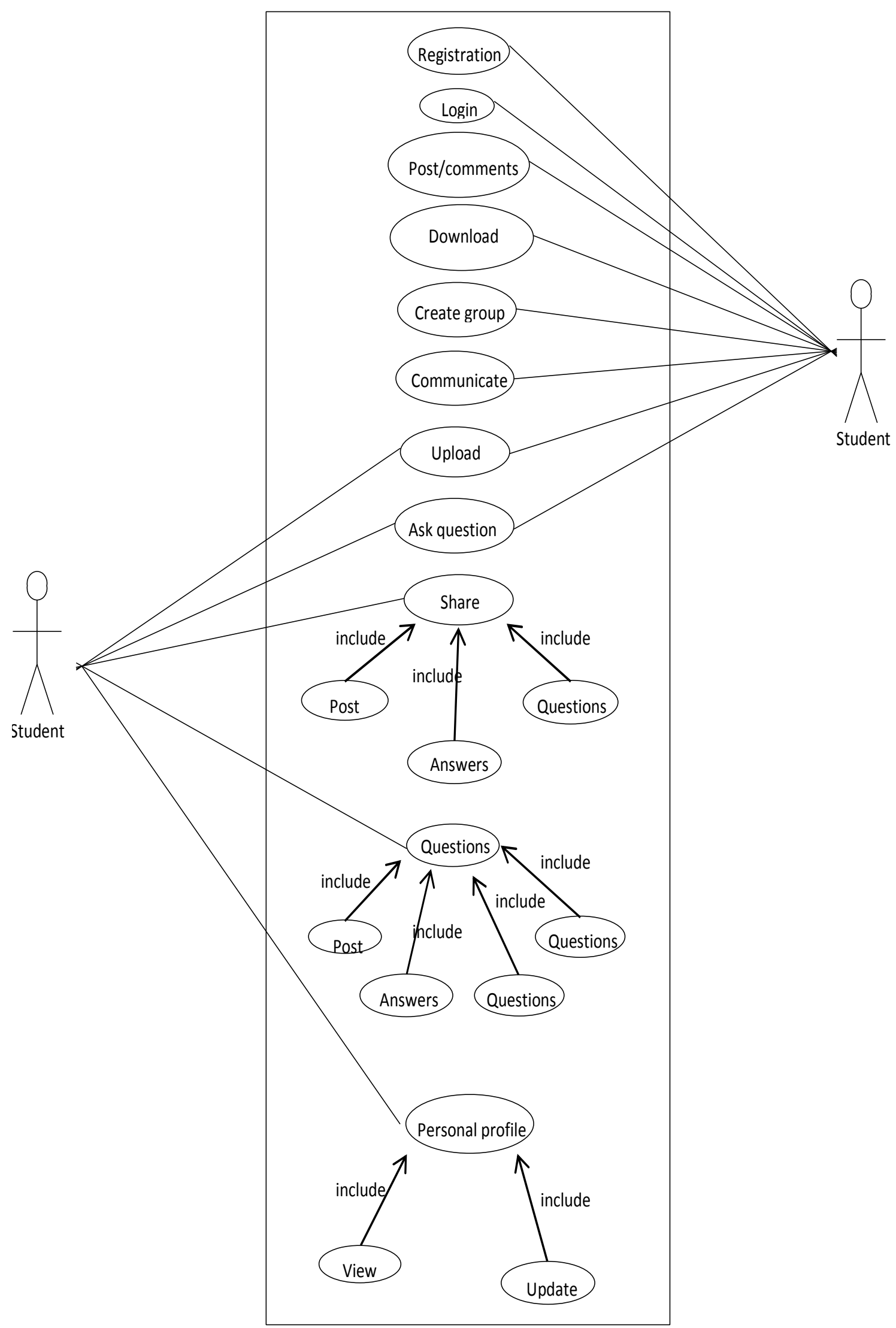

Figure 3: Use Case Diagram Showing Student Interaction with the System 


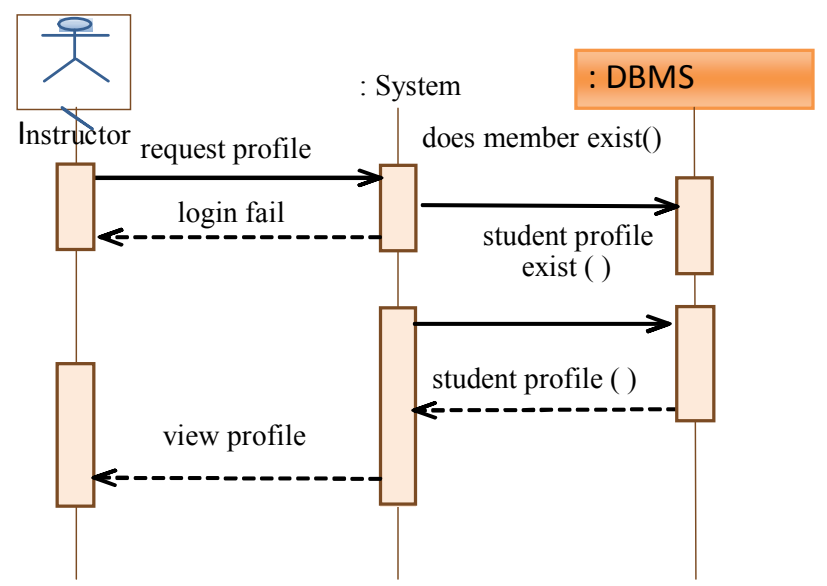

Figure 4: Sequence Diagram Showing Instructor View Student Profile Process

\section{RESULTS AND DISCUSSION}

The proposed prototype was developed using programming tools such as extensible hypertext markup language (xHTML), hypertext processor (PHP), MySQL under window environment, JQuery and Java Scripts. Also Concept Draw was used as an UML tool for analysis and design specifications. Additionally Macromedia Dreamweaver was used to makes it easier to edit coding for the chosen PHP (Hypertext preprocessor) codes. The actors of the system are: Administrator, Instructor, and student.

The Administrators have full authority to:

- Manage system

- $\quad$ Manage students

- $\quad$ Manage instructors

- Manage course information

- View users

- View groups

- View courses

The student has authority to:

- $\quad$ Post text, photo, music, video, link, pdf or word.

- Comment and/or like on the post or on other comment.

- Download or uploads materials.

- Create groups and join in available groups.

- Ask and answer to different questions

- Share posts, answers or questions.
- View his/her profile.

The instructor has authority to:

- Post, comment and/or like on the posts.

- Download or uploads different material.

- Share post, answer and questions.

- View student profile.

- View group profile.

- Rate the group or rank it due to their posts, comments and discussion.

The proposed prototype is called "LearnZoom". The proposed prototype consists of two main modules which allow user to interact with the system; Users' management module and Settings management module. For Users' Management Module, Learnzoom system user will have to provide first name, last name, e-mail address, course and password in which will be stored in the system database and hence the system must manage these information while in Settings Management Module, Group maker will have the full control in managing the group such that confirming the user request in joining into the group, adding the user and deleting the user in the group and for System administrator has the full control in the system such that updating user information, viewing the users' accounts and deleting the user. The proposed prototype is a web-based learning system that provides:

- An efficient and easy learning platform that students can interact with.

- A simple user interface that facilitates the interaction with the system.

- Administration tools that provide capabilities for implementing online discussions. 


\section{(1D) LearnZoom}

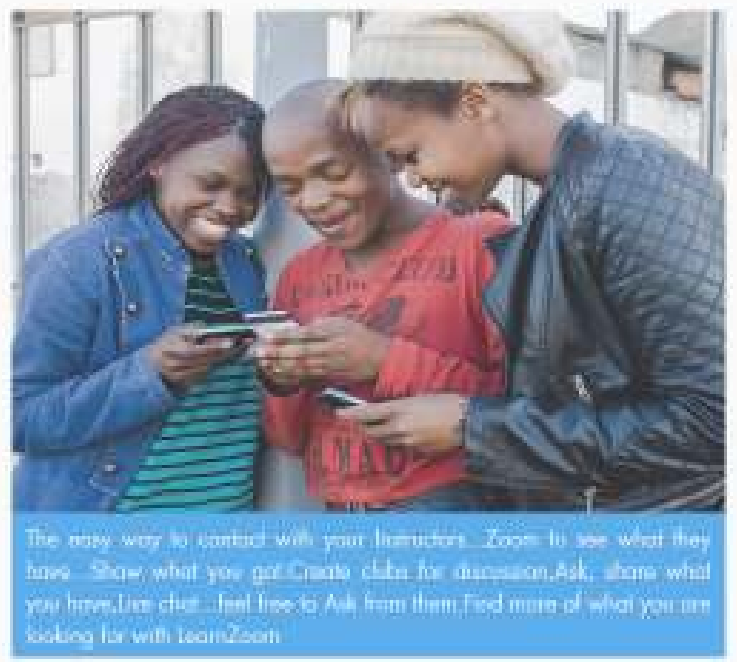

\section{Sign up now}

and sturt seeking knowledge and keoming

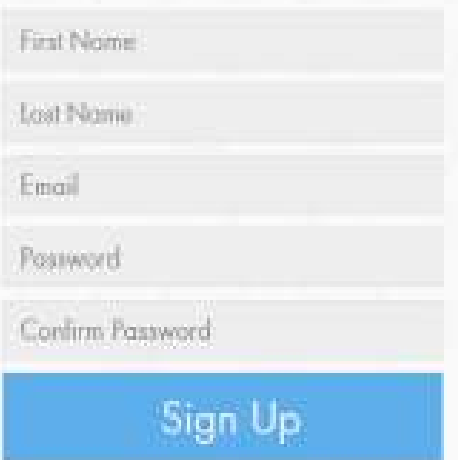

Figure 5: Welcome Page

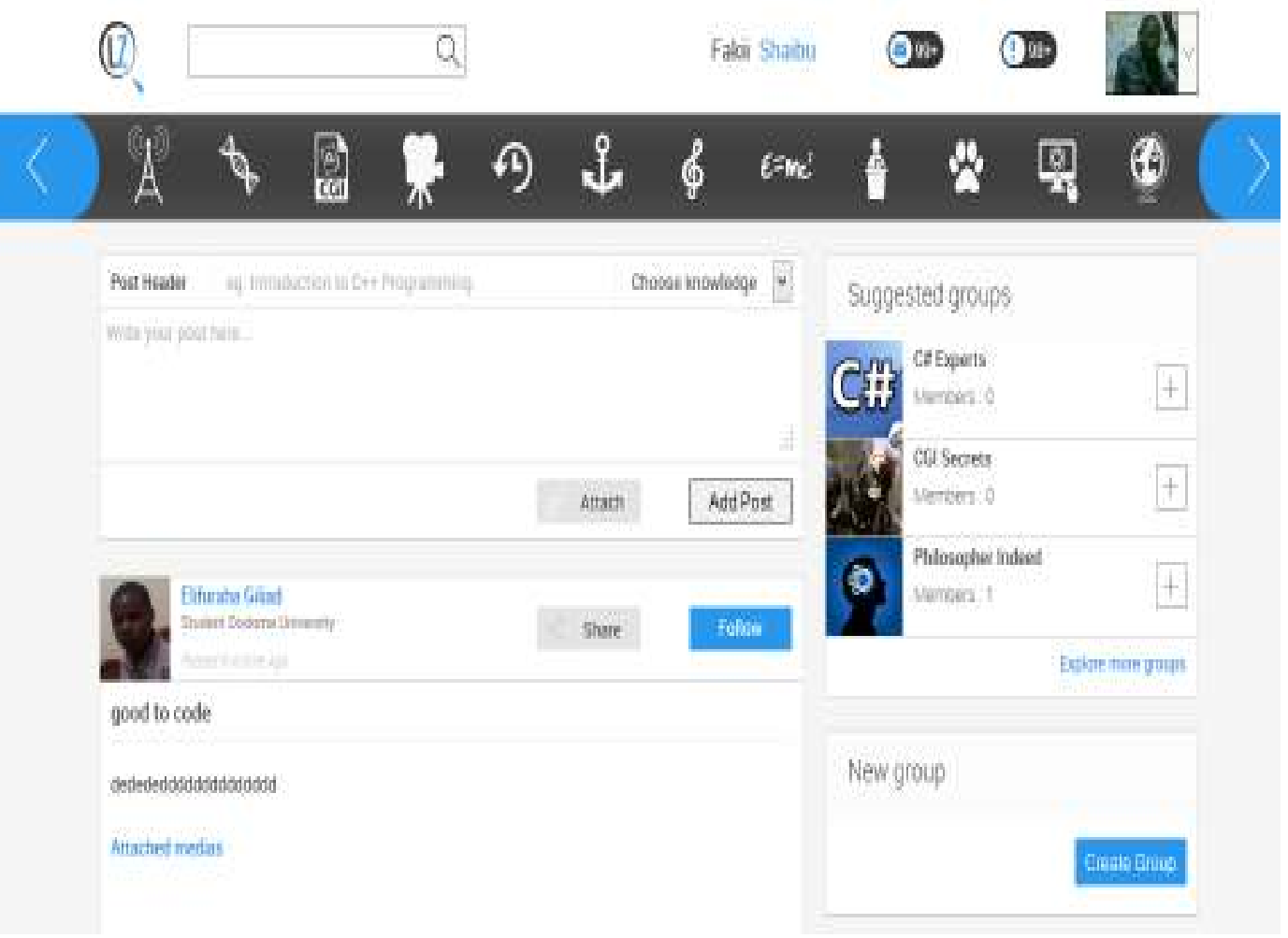

Figure 6: Home Page 


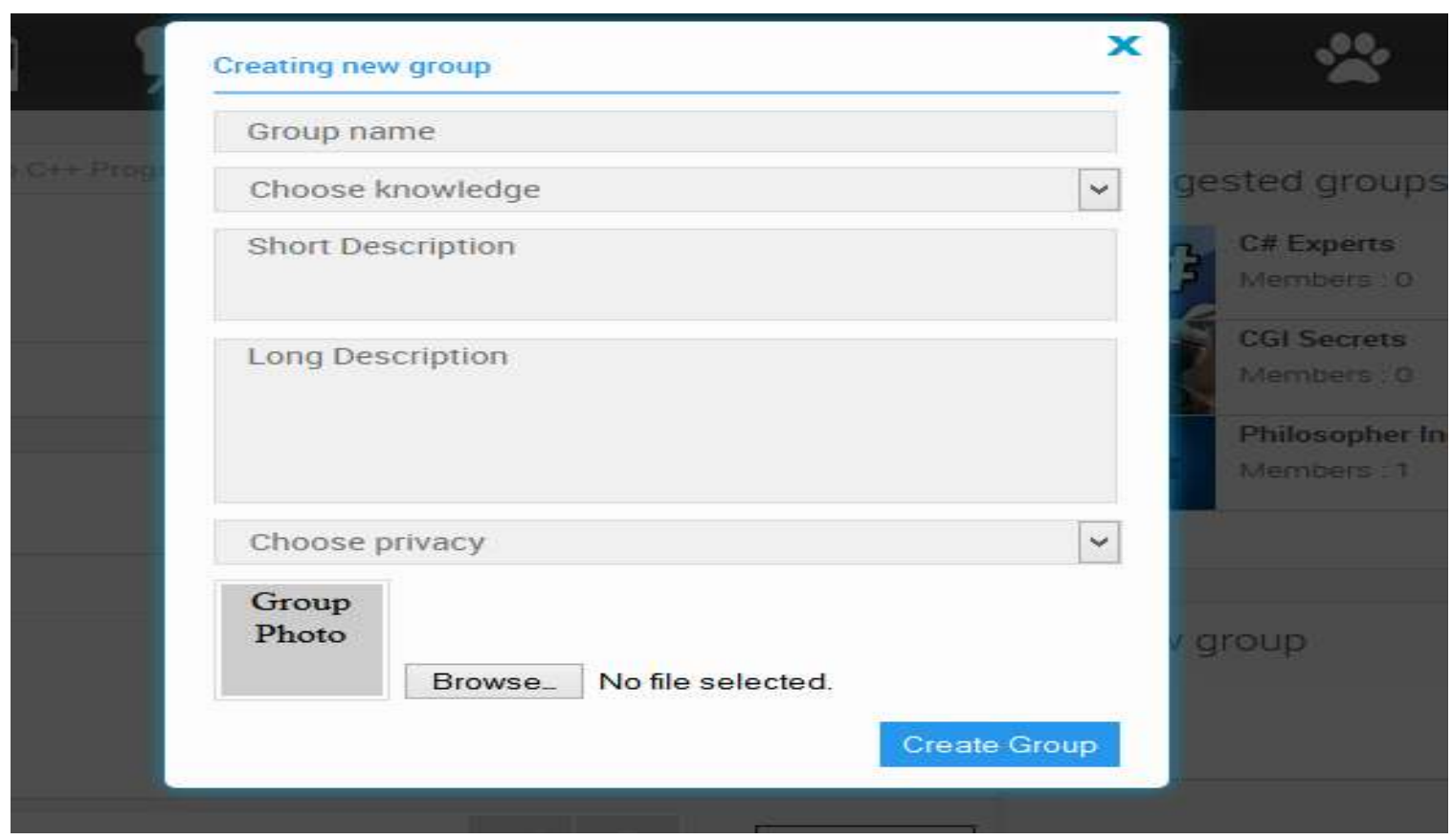

Figure 7: Creating a Group

\section{CONCLUSION}

Generally, it is important for institutions to be aware of students' current needs and interest related to their learning environment for better knowledge acquisition and academic achievement as they need more interactive learning environment that allows them to have greater chances to manage and control their own learning environment. Students' tendencies, inclinations and ability can be used to design and devise OSNs which may be more preferable to students and other users.

\section{FUTURE WORK}

The scope of this prototype was to propose a prototype on using OSNs as e-learning platforms in Tanzanian Universities' students. In that case further study should be conducted to develop the whole system that includes other requirements which were mentioned. These requirements include the ability of the system to allow instructors to rank and rate the answers and comments posted by the students as well as involve administrator from the institution to give assistance to students who have problems in joining the groups and accessing the site.

Also to design specifications that tackles a different kind of instructors' participation in the platform. Instructors' area will be designed in order to allow a special kind of profiling that would eliminate the mandatory link to educational institutions for getting trustworthy to the data.

\section{REFERENCES}

[1] Bertolino,A., Fantechi,A., Gnesi, S., and Lami, G.( 2002), "Use Case Description of Requirements for Product Lines", International Workshop on Requirements Engineering for Product Lines, pp. 12-18.

[2] DiMicco, J., Millen, D.R., Geyer, W., Dugan, C., Brownholtz, B. and Muller, M. (2008), "Motivations for Social Networking at Work", Computer supported cooperative work.
[3] Donnell, H. (2010), "Burger King 'bullied' staffer over Facebook post", [http://www.nzherald.co.nz/nz/news/article.cfm?c_id=1a ndobjectid=10704072], site visited on 19/2/2014.

[4] Dron, J., and Anderson, T. (2009a). How the crowd can teach. In S. Hatzipanagos and S. Warburton (Eds.), Handbook of research on social software and developing community ontologies (pp. 1-17). Hershey, PA: IGI Global Information Science.

[5] Golden, B., Hughes, N., McCabe, J., and Roberts, G. (2009), Facebook Participation, [http://xwiki.cs.colorado.edu/bin/download/DCNM2009/ A7ParticipationSpectrum/Fac130ebook ParticipationFinalPaper1.pdf], site visited on 09/07/2014.

[6] Green, H., Facer, K., Rudd, T., Dillon, P. and Humphreys, P. (2007), Personalization and Digital Technologies, Futurelab, Bristol.

[7] Ito, M., Okabe, D., and Matsuda, M. (2006), Personal, Portable, Pedestrian, MIT Press, Massachusetts.

[8] Liu, L. and Wang, C. (2009) E-learning Tools to Improve Students Learning Experience: a case study, International Journal of Modern Education and Computer Science (IJMECS), Vol. 1, No. 1, pp. 1-9

[9] Lu,W., Cai, G., Liu,W., and Weiwei X. (2012), "Interactive and Collaborative E-Learning Platform with Integrated Social Software and Learning Management System", Proceedings of the International Conference on Information Technology.

[10] McCann, K. H. (2009), "Virtual communities for educators: An overview of supports and best practices", Technology, Colleges, and Community Conference (pp. 137-142).

[11] McLoughlin, C., and Lee, M. J. W. (2010). Personalised and self regulated learning in the Web 2.0 era: 
International exemplars of innovative pedagogy using social software. Australasian Journal of Educational Technology, 26(1).

[12] Notley, T.M. and Tacchi, J.A. (2005) , "Online Youth Networks: Researching the Experiences of 'Peripheral' Young People in Using New Media Tools for Creative Participation \& Representation in 3CMedia", Journal of Community, Citizen's and Third Sector Media and Communication 1(1). pp. 73-81.

[13] Pempek, T. A., Yermolayeva, Y. A., and Calvert, S. L. (2009), "College students' social networking experiences on Facebook", Journal of Applied Developmental Psychology, 30(3), 227-238.

[14] Rosenberg, M. (2001), "E-learning: strategies for delivering knowledge in the digital age", The United States of America, The McGraw-Hill Companies, Inc.

[15] Schmugar, C. (2008), "The future of social networking sites", McAfee Security Journal,28-30.
[16] Schroeder A., Minocha S., and Schneider C. (2010). The strengths, weaknesses, opportunities, and threats of using social software in higher and further education teaching and learning. Journal of Computer Assisted Learning 26, $159-174$.

[17] Seif, H. (2012), Investigation of the challenges facing the implementation of on-line learning program for higher learning institutions: Case of Udom, Unpublished Report, UDOM.

[18] Titus, C. and Mselle, L. (2015), Investigating the viability of using online social networks as e-learning platforms in Tanzanian universities: Journal of Informatics and Virtual Education 03,40-43.

[19] Visual Paradigm for UML 8.0 Community Edition, 2010.www.visualparadigm.com/product/vpuml/editions/ community.jsp 